\title{
A situação dos hospitais quanto ao gerenciamento dos aspectos e impactos ambientais
}

\section{The situation of hospitals in what concerns the management of environmental aspects and impacts}

\author{
Elisete Dahmer Pfitscher ${ }^{1}$ \\ Bernadete Limongi \\ Eleonora Milano Falcão Vieira \\ Margarete Petry Pfitscher ${ }^{4}$ \\ Paulo César Pfitscher ${ }^{5}$
}

\begin{abstract}
Resumo
A situação dos hospitais, quanto ao gerenciamento dos aspectos e impactos ambientais, tem sido um tema discutido por vários pesquisadores, pelas sérias dificuldades existentes quanto ao sistema de tratamento dos resíduos gerados e pela falta de conhecimentos. O lixo hospitalar faz com que aumentem as deficiências na estrutura organizacional dessas instituições, decorrentes do núnero crescente de pacientes e das carências existentes que impossibilitam suprir as necessidades da população. Nesse sentido, este artigo tem por objetivo avaliar como essas instituições gerenciam os impactos ambientais. Utiliza-se a metodologia Gaia (Gerenciamento de Aspectos e Impactos Ambientais), através de entrevistas semi-estruturadas e lista de verificação, em um estudo de caso de um hospital. Após a análise dos resultados, verifica-se a classificação de sustentabilidade dos critérios: fornecedores, ecoeficiência do processo hospitalar, tratamento dos pacientes, indicadores gerenciais e os recursos humanos na organização. No final, é apresentada a planilha de identificação e com prioridade nos aspectos e impactos ambientais.
\end{abstract}

Palavras-chave: gerenciamento; aspectos e impactos ambientais; hospital.

\begin{abstract}
The situation of hospitals in what concerns the management of environmental aspects and impacts has been an issue widely discussed by several researchers, due to the serious problems regarding the treatment of the waste and the lack of knowledge about it. Hospital waste makes the deficiencies in such organizational structures increase since there is an increasing number of patients and shortage of supplies that make it impossible to satisfy the necessities of the population. Thus, the present article aims at evaluating how hospitals deal with environmental impacts. It was used a methodology named GAIA (The Management of Environmental Aspects and Impacts), through semistructured interviews and lists of verification applied in a case study of a hospital. After the analysis of the results, the classification of sustainability of some criteria is verified, such as furnishers, ecoefficiency of the hospital procedures, the treatment of patients, management indicators and the priorization of environmental aspects and impacts. The latter item involves the assessment of activities and commercial and environmental concerns.
\end{abstract}

Key words: management; environmental aspects and impacts; hospital.

\footnotetext{
1 Doutora em Engenharia de produção. Professora da UFSC. Endereço: Campus Trindade - Universidade Federal de Santa Catarina - Trindade. Florianópolis/Santa Catarina - Brasil - CEP: 88010970. E-Mail : elisete@ cse.ufsc.br

2 Doutora em Letras. Afiliação: Professora da UFSC. Endereço: Campus Trindade - Universidade Federal de Santa Catarina - Trindade. - Florianópolis/Santa Catarina - Brasil - CEP: 88010970.. Email: bernadete@cse.ufsc.br

3 Doutora em Engenharia e Gestão do Conhecimento. Afiliação: UFSC. Endereço: Campus Trindade - Universidade Federal de Santa Catarina - Trindade. Florianópolis/Santa Catarina - Brasil - CEP: 88010970. E-Mail : eleonorafalcao@gmail.com

4 Especialista na área da saúde. Afiliação: Grupo Hospitalar Conceição (Hospital Nossa Senhora da Conceição S.A.,Endereço: Av. Francisco Trein, $n^{\circ}$ 596. Cristo Redentor. Porto Alegre/RS - Brasil. Email: pdahmer@uol.com.br

5 Mestre Engenharia de Produção: Funcionário da Caixa Econômica Federal. Endereço: Rua Mário Candido da Silva, 46. Itaguaçu - Florianópolis./ SC - Brasil. CEP : 88085-475. E-mail: pdahmer@uol.com.br
}

Artigo recebido em setembro de 2006 


\section{Introdução}

O mercado competitivo e o atual padrão de consumo conduzem a problemática ambiental existente também às unidades de saúde. Existem ainda exigências dos órgãos fiscalizadores de preservação do meio ambiente e uma legislação que rege e dita normas e procedimentos adequados às atividades dessas instituições. Surge, pois, a necessidade de se ter políticas voltadas para o gerenciamento de aspectos e impactos ambientais, a fim de, além de melhorar a qualidade do tratamento dos pacientes, evitar, também, os impactos negativos ao meio ambiente e obedecer à legislação.

O aumento da quantidade de pacientes nas clínicas de saúde e hospitais, associado às deficiências das estruturas organizacionais, fez surgir a necessidade da criação de processos e organizações capazes de reciclar e tratar esses resíduos hospitalares, a exemplo do que vem ocorrendo em outros países, tais como Holanda, Japão e Suíça, onde a prática de aterrar, no entendimento deles, traz um ônus irreversível, devendo ser restrita ao mínimo possível. Nesse sentido, são instaladas usinas de incineração desses materiais, tranformados assim em matriz energética de novos processos produtivos.

A problemática existente consiste em verificar a quantidade de resíduos existentes em cada setor e então conscientizar os atores envolvidos quanto à importância de se aplicar formas de valorização do meio ambiente. Uma vez que isso ocorra, passa a haver o comprometimento das instituições. Assim, aplica-se num hospital a metodologia Gaia, que é dividida em critérios e subcritérios, para mostrar aos gestores dessa instituição onde se situam as falhas porventura existentes e como solucioná-las. Usa-se o método como uma ferramenta capaz de mostrar o resultado do processo, através de uma planilha de identificação e priorização de aspectos e impactos ambientais. Nela são mostradas as preocupações comerciais e ambientais, a fim de que os gestores possam tomar suas decisões e, assim, obter sustentabilidade econômica e ambiental.

\section{Metodologia}

O conjunto de técnicas adotadas pelo investigador/pesquisador para construir a realidade da pesquisa a fim de diagnosticar a instituição pesquisada mostra uma compreensão analítica do problema. Trata-se, neste estudo, de uma pesquisa participativa, caracterizada pela interação entre o pesquisador e o pesquisado no processo (BEUREN, 2002). A trajetória metodológica desenvolve-se em três fases distintas: revisão teórica, estudo de caso e análise dos resultados.

Na primeira fase tem-se, inicialmente, o levantamento bibliográfico e documental. Em seguida, na segunda fase, o estudo de caso com entrevistas semi-estruturadas. Segundo Merrian (1998), um dos aspectos importantes de um estudo de caso é que ele permite, num primeiro momento, explicar a razão do problema, a situação vivenciada, o porquê do que está acontecendo, depois disso, o porquê da inovação do trabalho e, ainda, num terceiro momento, a possibilidade de se discutir novas alternativas. São entrevistados, então, os gestores de uma unidade hospitalar; um da área técnica e o outro da área administrativa.

A terceira fase envolve a interpretação dos dados, o conhecimento do ambiente onde se está atuando e a descoberta das situações in loco, mostrando-se, nessa fase, a planilha de prioridades de aspectos e impactos ambientais para apresentar o plano resumido de gestão ambiental.

\section{Revisão teórica}

A preocupação com questões ambientais e responsabilidade social faz com que as empresas procurem fornecedores que atendam a seus requisitos éticos e que também os insumos produtivos estejam em conformidade com os requisitos ambientais (TACHIZAWA, 2004, p.68). 
Mudanças e transformações quanto à gestão ambiental, hoje, ocorrem também na administração de hospitais. Anteriormente, a gestão ambiental era prerrogativa só de grandes empresas, que a utilizavam somente por uma questão de marketing, para mostrar o quanto estavam envolvidas com questões de valorização do meio ambiente. Atualmente, a preocupação também é com a saúde.

Assim, o gerenciamento de aspectos e impactos ambientais começa a ter uma importância maior, principalmente, quando a intenção é gerar e proporcionar cada vez mais saúde aos pacientes. Dessa perspectiva, nesta seção é apresentado um estudo sobre a gestão ambiental, o Gaia (Gerenciamento de Aspectos e Impactos Ambientais), e o tratamento dos resíduos nas unidades hospitalares.

\section{A gestão ambiental}

As estratégias de gestão ambiental e responsabilidade social ocorrem de forma diferenciada, em função do tipo de empresa, e deveriam ser inovadoras, acompanhando as necessidades do mercado e do ambiente onde estão situadas as empresas (TACHIZAWA, 2004, p.33).

A sociedade, após várias catástrofes ambientais, verifica que o desenvolvimento tecnológico pode andar paralelamente com a preservação do meio ambiente, buscando estratégias que possibilitem um desenvolvimento sustentável. O homem percebeu que depende da natureza e que precisa preservá-la para amenizar a situação ambiental (PFITSCHER et al, 2002, p.5).

Diariamente, nas diversas organizações existentes, os gestores manifestam preocupação quanto aos impactos ambientais que suas atividades estão causando ao meio ambiente, revelando que amenizar a situação ambiental é uma função necessária.

A proteção do meio ambiente e a sua preservação fazem com que exista uma conscientização maior por parte dos gestores das empresas, e a sociedade, por sua vez, está mais consciente e receptiva a aspectos de marketing ecológico. Segundo Tachizawa (2004, p.26):

A nova consciência ambiental, surgida no bojo das transformações culturais que ocorreram nas décadas de 60 e 70, ganhou dimensão e situou o meio ambiente como um dos princípios fundamentais do homem moderno. Nos anos 80, os gastos com proteção ambiental começaram a ser vistos, pelas empresas líderes, não primordialmente como custos, mas como investimentos no futuro e, paradoxalmente, como vantagem competitiva.

Assim, os gestores começam a considerar que a existência de fumaça não é uma vantagem e sim uma anomalia e estudam processos de melhoria contínua em suas instituições. O compromisso com a melhoria contínua pode ser obtido com uma política ambiental relacionada à natureza e aos impactos ambientais das atividades das empresas, sendo, então, possível adotar uma gestão ambiental, com a necessidade de avaliações dos procedimentos internos e externos e mostrando ações corretivas e preventivas (PFITSCHER, 2004, p.67).

Segundo Tachizawa (2004, p.161):

O impacto ambiental é diferenciado em função do tipo de organização. O mundo empresarial, que é constituído pelas organizações que constituem a economia do país, pode ser considerado como um conjunto de diferentes classes (famílias ou grupamentos) de empresas, afins entre si, em termos de características organizacionais.

O autor, de certa forma, coloca a necessidade de se estudar as empresas separadamente, pela sua finalidade básica e pelo fato de apresentarem características específicas. No caso deste artigo, os estudos são direcionados para aspectos e impactos ambientais num hospital. Para tanto, são verificadas as suas atividades, a trajetória dos 
equipamentos nos diversos setores, para só depois serem analisados os impactos ambientais. Para essa finalidade, utiliza-se como ferramenta o método Gaia.

\section{O Gaia (Gerenciamento de Aspectos e Impactos Ambientais)}

A tomada de decisão pelos gestores, quanto ao desempenho ambiental de suas instituições, leva em consideração também a importância dos ecossistemas, que passam a ser uma preocupação constante, pela cobrança da sociedade, fazendo com que essa opção pela proteção ao meio ambiente seja referenciada nos objetivos e metas, sendo, ainda, constantemente discutida pelos administradores.

Assim, surge o método Gaia para auxiliar os gestores nas tomadas de decisão. Esse método tem como finalidade assessorar os gestores das empresas, mostrando os impactos ambientais que suas decisões possam estar causando e mostrando algumas alternativas para a melhoria do desempenho ambiental.

O método Gaia foi desenvolvido pelo professor Lerípio, como resultado de sua tese de doutorado. Trata-se de um instrumento para alcançar a melhoria do desempenho ambiental das organizações e o alcance da sustentabilidade. Tem como princípios:

Proporcionar às organizações o atendimento à legislação, a melhoria contínua e a prevenção da poluição a partir de atividades focalizadas no desempenho ambiental e na sustentabilidade, tomando como elementos fundamentais do processo a organização e as pessoas através de suas relações com o meio ambiente. (LERÍPIO, 2001, p.66)

O Gaia surgiu, então, para valorizar o meio ambiente, mostrando aos administradores das empresas o desempenho ambiental dos setores das organizações, conscientizando e sensibilizando a área de recursos humanos nelas inserida. Valoriza, também, o público consumidor, uma vez que, ao verificar o impacto ambiental, atua na sociedade. Sabe-se, ainda, que é de suma importância conhecer a empresa pesquisada. Esse método é composto de três fases, conforme o quadro 1. 
Quadro 1 - Resumo das fases e atividades do método Gaia, com base na aplicação da empresa pesquisada

\begin{tabular}{|c|c|c|c|c|}
\hline Fases & Descrição & Objetivo & Atividades & Resultados \\
\hline \multirow{3}{*}{1} & \multirow{3}{*}{ Sensibilização } & \multirow{3}{*}{$\begin{array}{l}\text { Comprometer a } \\
\text { alta administração } \\
\text { com a melhoria } \\
\text { contínua do } \\
\text { processo }\end{array}$} & $\begin{array}{l}\text { Sustentabilidade do } \\
\text { negócio }\end{array}$ & $\begin{array}{l}\text { Conhecimento do nível atual do desempenho } \\
\text { ambiental }\end{array}$ \\
\hline & & & Estratégia ambiental & $\begin{array}{l}\text { Comparação do desempenho atual com } \\
\text { aquele apresentado por filosofias defensivas, } \\
\text { reativas, indiferentes e inovadoras de } \\
\text { gerenciamento }\end{array}$ \\
\hline & & & $\begin{array}{l}\text { Comprometimento e } \\
\text { sensibilização das } \\
\text { partes interessadas }\end{array}$ & $\begin{array}{l}\text { Missão, visão, política e objetivos. } \\
\text { Sensibilização dos colaboradores, } \\
\text { fornecedores, da comunidade, dos órgãos } \\
\text { ambientais e dos clientes }\end{array}$ \\
\hline \multirow{3}{*}{2} & \multirow{3}{*}{ Conscientização } & \multirow{3}{*}{$\begin{array}{l}\text { Identificar a cadeia } \\
\text { de produção e } \\
\text { consumo }\end{array}$} & $\begin{array}{l}\text { Mapeamento da cadeia } \\
\text { de produção e } \\
\text { consumo }\end{array}$ & $\begin{array}{l}\text { Identificação da cadeia do ciclo de vida do } \\
\text { produto }\end{array}$ \\
\hline & & & $\begin{array}{l}\text { Mapeamento do } \\
\text { macrofluxo do } \\
\text { processo }\end{array}$ & $\begin{array}{l}\text { Identificação das etapas do processo } \\
\text { produtivo da organização-alvo }\end{array}$ \\
\hline & & & $\begin{array}{l}\text { Estudo de entradas e } \\
\text { saídas dos processos e } \\
\text { inventário de aspectos } \\
\text { e impactos ambientais }\end{array}$ & $\begin{array}{l}\text { Identificação das matérias-primas e demais } \\
\text { itens de cada etapa do processo }\end{array}$ \\
\hline \multirow{3}{*}{3} & \multirow{3}{*}{$\begin{array}{l}\text { Capacitação ou } \\
\text { qualificação }\end{array}$} & \multirow{3}{*}{$\begin{array}{l}\text { Qualificar os } \\
\text { colaboradores para } \\
\text { definir e } \\
\text { implementar as } \\
\text { melhorias no } \\
\text { desempenho } \\
\text { ambiental }\end{array}$} & $\begin{array}{l}\text { Identificação de } \\
\text { oportunidades de } \\
\text { melhoria }\end{array}$ & $\begin{array}{l}\text { Alternativas de soluções para os principais } \\
\text { aspectos e impactos }\end{array}$ \\
\hline & & & $\begin{array}{l}\text { Estudo da viabilidade } \\
\text { técnica, econômica e } \\
\text { ambiental }\end{array}$ & $\begin{array}{l}\text { Solução mais viável sob os pontos de vista } \\
\text { técnico, econômico e ambiental }\end{array}$ \\
\hline & & & Planejamento & Visão geral do conjunto do plano de ação \\
\hline
\end{tabular}

Fonte: adaptado de Lerípio (2001 p.68).

As três fases mencionadas são a de sensibilização, a de conscientização e a de capacitação ou qualificação. Cada uma delas possui características distintas, conforme especificado adiante.

\section{Sensibilização}

Compreende a sustentabilidade do negócio, a estratégia ambiental, o comprometimento e a sensibilização das partes interessadas. É nessa fase que são levantadas as questões quanto aos trâmites das funções nas empresas, através de uma lista de verificação. A lista é dividida em critérios e subcritérios, conforme as atividades da empresa que se pretende estudar.

As respostas são determinadas de acordo com o seguinte critério: A (adequado); D (deficitário) e NA (não se adapta). A primeira é considerada boa prática, a segunda mostra problemas ou necessidade de melhoria e a 
terceira, que não se aplica à empresa. Isso altera a versão inicial do método Gaia, que vinha sendo determinado por cores.

A sustentabilidade do negócio, primeira atividade desta fase, é avaliada com base na fórmula: total de quadros "A" $x 100$ no numerador e total de questões menos total de quadros "NA" no denominador. Utiliza-se esse mesmo procedimento para cada um dos subcritérios.

Quanto à estratégia ambiental, ela apresenta uma posição que representa a sustentabilidade de cada critério e subcritério. Segundo Lerípio (2001, p.73), “As inferências abordam as correlações entre a classificação da sustentabilidade e o nível de desempenho, o atendimento à legislação, a situação ambiental atual e a percepção da empresa". Nesse sentido, o quadro 2 apresenta as correlações entre sustentabilidade e desempenho ambientais.

\section{Quadro 2 - Correlações entre sustentabilidade e desempenho ambiental da empresa pesquisada}

\begin{tabular}{lll}
\hline $\begin{array}{l}\text { Classificação da } \\
\text { sustentabilidade }\end{array}$ & $\begin{array}{l}\text { Nível de } \\
\text { desempenho }\end{array}$ & Atendimento à legislação \\
\hline “A" & Adequado & Atendimento pleno \\
\hline "R" & Regular & Atendimento baseado em controle/correção \\
\hline "D" & Deficitário & Não atendimento \\
\hline & Fonte: adaptado de Lerípio (2001 p. 68).
\end{tabular}

Após essa análise, os itens deficitários são estudados para que numa próxima aplicação não apareçam nessa posição. Se forem de fraca percepção e exigirem pouco esforço para controlar a poluição, futuras ações poderão ser encaminhadas.

A terceira atividade desta primeira fase, comprometimento e sensibilização de partes interessadas, apresenta como uma de suas formas, proporcionar conhecimento da valorização do meio ambiente e sensibilizar as partes interessadas através de palestras e minicursos. Para se identificar onde deve ser a atuação, é necessário compreender a trajetória das atividades na empresa.

\section{Conscientização}

A percepção dos aspectos ambientais que possam causar impacto ao meio ambiente depende da tramitação do produto dentro da empresa; ou seja, é preciso identificar o ciclo de vida do produto e verificar sua interferência. Nesse sentido, esta fase mostra o mapeamento da cadeia de produção e consumo, o macrofluxo do processo, os estudos de entradas e saídas dos processos e o inventário de aspectos e impactos ambientais.

A primeira atividade desta fase, "cadeia de produção e consumo", tem como objetivo verificar setores impactantes e procurar situações de melhoria, já que se tem um contato direto com a organização. É estudado desde a chegada dos produtos às empresas até sua expedição ou utilização final.

A segunda atividade da fase de conscientização, o "mapeamento do macrofluxo do processo", compreende: fornecedores, recebimento do produto na empresa e ecoeficiência do processo até expedição e distribuição logística ou, no caso de hospitais, tratamento com pacientes.

Quanto à terceira atividade desta fase, "estudo de entradas e saídas dos processos e inventário de aspectos e impactos ambientais", pode-se evitar desperdícios e sinalizar pontos falhos. Isso ocorre quando se verifica a 
quantidade de materiais que saem e que entram na empresa e os impactos que estes causam no processo produtivo. (LERÍPIO, 2001, p. 77).

O conjunto das atividades apuradas através de levantamentos pode mostrar situações de impactos ambientais. Trata-se, então, de uma descrição minuciosa, mostrando o seu aspecto, o impacto causado e as preocupações comerciais e ambientais, com uma análise de prioridades, conforme mostra o Quadro 3.

\section{Quadro 3 - Escala de valores para prioridade de aspectos e impactos ambientais}

\begin{tabular}{ll}
\hline Avaliação & Valor Atribuído \\
\hline Extremamente crítica & 5 \\
\hline Crítica & 4 \\
\hline Moderada & 3 \\
\hline Desprezível & 2 \\
\hline Totalmente desprezível & 1 \\
\hline
\end{tabular}

Fonte: adaptado de Lerípio (2001, p.79).

Com a escala de valores, utiliza-se uma planilha de identificação e prioridade de aspectos ambientais. São utilizados raciocínios ilustrativos, a exemplo da empresa pesquisada: "a poluição do ar gerada na atividade recebimento de produto, através do aspecto poeira e suspensão, é extremamente crítica (5), crítica (4), moderada (3), desprezível (2) ou totalmente desprezível (1)?”. Analisando essa primeira atividade, chega-se à média das preocupações comerciais, de 2,5, e ambientais, de 3,0; portanto, a um somatório de 5,5, com prioridade 9. Esse resultado é mostrado no quadro 4.

Quadro 4 - Planilha de identificação e priorização de aspectos e impactos ambientais

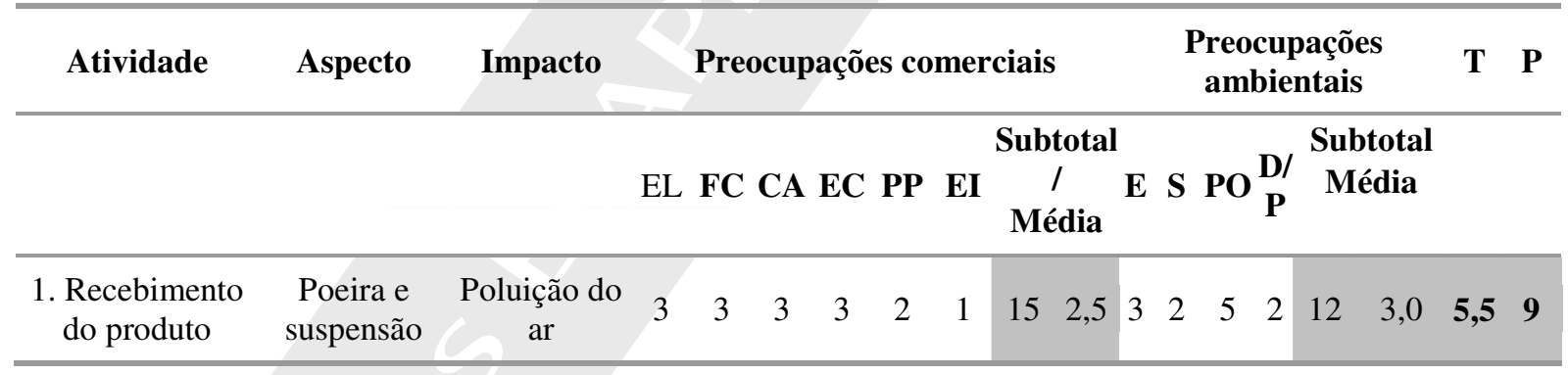

Fonte: adaptado de Pfitscher et al (2002, p.25).

Portanto, o preenchimento da planilha requer acompanhamento, com grande ênfase, do mapeamento do processo e estudo das entradas e saídas que servem de base para as três primeiras colunas. Em seguida, há o questionamento dos impactos em relação ao critério escala de valores para priorização de aspectos e impactos ambientais.

Para preencher as colunas relativas às preocupações comerciais, são utilizadas as siglas: EL - exposição legal da organização, uma vez ocorrido o impacto; FC - facilidade de correção do impacto; CA - custo de alteração do impacto; EC - efeitos colaterais; PP - preocupações do público com relação ao impacto e EI - efeitos do impacto sobre a imagem da organização. 
Quanto às preocupações ambientais, são utilizadas as siglas: $\mathrm{E}$ - escala do impacto; $\mathrm{S}$ - severidade do impacto; $\mathrm{PO}$ - probabilidade de ocorrência do impacto e D/P - duração/persistência.

\section{Capacitação ou qualificação}

Nesta fase são apresentadas as atividades: identificação de oportunidades de melhoria, estudo da viabilidade técnica, econômica e ambiental e o planejamento. Assim, mostra possibilidades de melhorar a qualidade dos serviços. A preocupação com funcionários que trabalham diretamente nas atividades é evidenciada nos esforços que a empresa direciona ao bem-estar de seus empregados, levando-os a um melhor relacionamento com os clientes que, no caso de hospitais, são os pacientes.

Na primeira atividade, "identificação de oportunidades de melhoria", são estudadas as situações que merecem atenção especial, informações vindas da planilha de identificação e prioridade de aspectos e impactos ambientais, relacionando os objetivos e metas para solucionar a problemática existente, conforme mostra o quadro 5.

\section{Quadro 5 - Proposta de relação entre objetivos e metas}

\begin{tabular}{ll}
\hline Objetivo (O que?) & Meta (Qual?) \\
\hline $\begin{array}{l}\text { Identificar possibilidades para eliminar poluição do } \\
\text { solo, no que se refere a outros resíduos sólidos }\end{array}$ & Tratamento e reutilização dos resíduos sólidos \\
\hline
\end{tabular}

Fonte: adaptado de Pfitscher (2004, p.94).

Traçados os objetivos e metas, cabe aos gestores verificar a possibilidade de se efetivar aquilo que está sendo relacionado como necessário para a empresa. Parte-se, então, para a segunda atividade, "estudo da viabilidade técnica, econômica e ambiental". Nesse momento, são relacionados os indicadores, a justificativa e os responsáveis pela atuação, conforme mostra o quadro 6.

Quadro 6 - Relações entre metas, justificativas e responsáveis

\begin{tabular}{|c|c|c|}
\hline Meta (Qual?) & Justificativa (Por quê?) & Responsável (Quem?) \\
\hline Tratamento e reutilização de resíduos sólidos & $\begin{array}{l}\text { Evitar impacto agravante e ver } \\
\text { outra forma de agregar valor à } \\
\text { empresa }\end{array}$ & Direção \\
\hline
\end{tabular}

Fonte: adaptado de Pfitscher (2004, p.95).

As justificativas devem ser de fácil compreensão, para depois serem determinados os gestores responsáveis pela correção do impacto que está causando a atividade considerada com maior prioridade de atendimento. O benchmarking ambiental das empresas do mesmo ramo é uma das práticas adotadas nessa atividade. A terceira atividade, "planejamento", envolve as áreas abrangidas, nas quais serão implementados os procedimentos, conforme mostra o quadro 7.

\section{Quadro 7 - Relações entre atividades, áreas abrangidas e procedimentos}

\begin{tabular}{lll}
\hline Atividades (Como?) & $\begin{array}{l}\text { Áreas abrangidas } \\
\text { (Onde - implementação?) }\end{array}$ & $\begin{array}{l}\text { Procedimentos } \\
\text { (Onde - registro?) }\end{array}$ \\
\hline $\begin{array}{l}\text { Pesquisa de mercado para venda dos } \\
\text { Na empresa e instituições } \\
\text { resíduos sólidos }\end{array}$ & $\begin{array}{l}\text { Fornecer projeto de } \\
\text { reaproveitamento }\end{array}$ \\
\hline
\end{tabular}

Fonte: adaptado de Pfitscher (2004, p.96) 
Uma avaliação parcial pode ser obtida a partir do quadro 8, que mostra as relações entre metas, atividades e avaliação. Assim, gradativamente, vai sendo analisada a situação em que a empresa se encontra.

Quadro 8 - Relações entre metas, atividades e avaliação

\begin{tabular}{|c|c|c|c|c|c|}
\hline Meta & Responsável & Atividade & Responsável & $\begin{array}{l}\text { Procedimentos de } \\
\text { avaliação }\end{array}$ & Parâmetro \\
\hline $\begin{array}{l}\text { Tratamento e } \\
\text { reutilização de } \\
\text { resíduos sólidos }\end{array}$ & Direção & $\begin{array}{l}\text { Pesquisa de } \\
\text { mercado para } \\
\text { venda dos } \\
\text { resíduos sólidos }\end{array}$ & $\begin{array}{l}\text { Administrador } \\
\text { da empresa } \\
\text { pesquisada e } \\
\text { extensionistas } \\
\text { da pesquisa }\end{array}$ & $\begin{array}{l}\text { Verificação in loco, } \\
\text { acompanhamento de } \\
\text { obras, inclusive das } \\
\text { instituições } \\
\text { pesquisadas }\end{array}$ & $\begin{array}{l}\text { Controle do } \\
\text { impacto }\end{array}$ \\
\hline
\end{tabular}

Fonte: adaptado de Pfitscher (2004, p.97)

Finalizadas as atividades de planejamento, apresenta-se o plano resumido de gestão ambiental, que contempla as metas e objetivos mostrados como prioritários para a empresa. Ainda aparecem as justificativas, as atividades e a maneira como foi realizado o trabalho. Tem-se, então, a utilização da ferramenta $5 W 2 H$ (What? Why? When? Where? Who?How?How much?), sugerida pelo autor do método, professor Lerípio.

\section{O tratamento dos resíduos nas unidades hospitalares}

O tratamento de resíduos é uma prática utilizada por vários países. Na Holanda, aterrar lixo é considerado uma prática com ônus irreversível às estruturas físicas e ambientais. Assim, ela é restrita ao mínimo possível, intensificando-se os procedimentos de recuperação e, também, instalando-se usinas de incineração de lixo, com recuperação de energia, dentro da capacidade adequada e de acordo com o planejamento previsto (WASTE INFORMATION SYSTEM, 1992).

No Japão, são incinerados $78 \%$ dos resíduos sólidos urbanos e existe a meta de atingir o nível de $100 \%$ (MECHLER, 1991). Na Suíça, o país incinera quase 80\% dos seus resíduos sólidos urbanos e tem como meta incinerar $100 \%$ dos combustíveis não-recicláveis.

Há ainda estudos que mostram que não será permitida, no futuro, a disposição do lixo em aterros em muitos países do mercado europeu. Existe uma legislação na Alemanha que regulamenta as atividades de aterro, limitando a emissão de carbono orgânico do material destinado a aterros em 3\% (SBRT, 2006).

\section{A disposição final de resíduos sólidos de serviços de saúde}

O tratamento adequado para resíduos de saúde pode ser considerado aquele que permita condições de segurança e eficiência e que possa modificar as características físicas, químicas e biológicas, ajustando-as a padrões aceitos legalmente como disposição final. Nesse sentido, o tratamento pode ocorrer por si só ou associado a um tratamento prévio que impeça a disseminação dos agentes patogênicos ou outra forma de contaminação, acima do que legalmente é aceito.

Esse processo de tratamento dos resíduos de saúde tem se diversificado, podendo serem realizados diferentes tipos de tratamento. Porém, há muito a ser feito para que o destino do lixo hospitalar possa ser considerado adequado pelas organizações de saúde e meio ambiente. Pesquisadores defendem a idéia de que o tratamento de resíduos deva ser realizado no próprio local onde foram gerados, treinando-se equipes das áreas de limpeza, manuseio e transporte. Assim, haveria um envolvimento dos atores no processo de conscientização ambiental e, dessa forma, seria possível mostrar não apenas as diferenças entre os resíduos infectantes, mas também as técnicas para se produzir menos lixos/resíduos. 
Em se tratando de resíduos hospitalares, não se trata de algo homogêneo. O acondicionamento, manuseio, transporte e tratamento são diferentes etapas que devem ser observadas uma a uma, com responsabilidade. Assim, o lixo hospitalar merece atenção em todas as suas fases até a disposição final.

Apenas 14\% dos resíduos hospitalares são devidamente tratados no Brasil. A maior parte ainda segue para lixões e aterros, gerando diversas formas de contaminação e poluição. Destacam-se dois métodos de tratamento dos resíduos de saúde: incineração e autoclavagem.

\section{Incineração}

Trata-se da queima do lixo em instalações chamadas "incineradores". Eles são utilizados para o tratamento de resíduos de alta periculosidade ou daqueles que necessitam de destruição completa e segura. É um processo de destruição térmica realizada sob altas temperaturas (entre $900^{\circ} \mathrm{C}$ e $1.250^{\circ} \mathrm{C}$ ), com tempo de permanência controlada (HTTP://WWW.SBRT.IBICT.BR).

Ocorre, então, a decomposição térmica, via oxidação a altas temperaturas, da parcela orgânica dos resíduos, atravessando uma fase gasosa e outra sólida, reduzindo, também, o volume, o peso e as características de periculosidade dos resíduos. Entretanto, é um método de alto custo pela utilização de equipamentos especiais.

Segundo o Serviço Brasileiro de Respostas Técnicas (SBRT, 2006), os resíduos (escórias e cinzas) resultantes do processo devem ser dispostos em aterros sanitários próprios e os efluentes líquidos, dispostos em estação de tratamento. Assim, as atividades são tratadas e monitoradas.

Nos dias de hoje, há vários tipos de incineradores, mas a sua utilização apresenta muitos inconvenientes. Considera-se como o problema mais grave desse método a poluição do ar pelos gases da combustão e por partículas não retidas nos filtros e precipitadores. "Os gases remanescentes da incineração do lixo são: anidrido carbônico (CO2); anidrido sulfuroso (SO2); nitrogênio (N2); oxigênio (O2); água (H2O) e cinzas". (ESSENCIS, 2006).

A razão disso é que o lixo hospitalar é geralmente acondicionado em sacos plásticos e colocados manualmente nos pequenos incineradores. Além disso, a incineração é a céu aberto, sem tratamento dos gases e vapores gerados pelo processo de queima.

Segundo Essencis (2006, p.9): “O sucesso da incineração pode ser fortemente afetado pela diversidade dos resíduos e suas embalagens, visto que, para alguns tipos de resíduos, a incineração não é recomendada ou até mesmo é perigosa". Pode ser então altamente danosa por liberar na atmosfera, além do gás carbônico, compostos de enxofre, nitrogênio, fósforo e, o que é pior, estruturas organocloradas, que são tóxicas e cancerígenas.

\section{Autoclavagem}

O processo de destinação dos resíduos sólidos por meio do equipamento "autoclave" segue alguns procedimentos. O lixo é coletado em sacos plásticos, na cor branco leitosa, conforme especificação da norma ABNT, ou nos recipientes apropriados. Estes são depositados em caixas metálicas sem tampa, sem que haja necessidade de abri-los. O vapor é injetado na câmara da autoclave para permitir a esterilização. Com a alta temperatura, esses sacos são destruídos, permitindo o contato do vapor com o lixo que será esterilizado. A partir daí, o lixo é triturado e estará em condições de ser encaminhado para um aterro sanitário para o depósito final (BAUMER, 2006).

Segundo Pinto (2005, p.7): 
O lixo triturado, ensacado ou em container deve ser armazenado sobre base impermeabilizada com caimento para caixa de coleta, para recolher o chorume (líquido resultante da decomposição) que porventura for formado e permitir o seu tratamento através de produtos químicos. Os líquidos que resultarem da lavagem dos containers e do triturador devem ser encaminhados para a mesma caixa de coleta.

Assim, os efluentes podem ser tratados e encaminhados para uma rede de esgoto ou, ainda, para fossas de decantação. Possuem apenas carga orgânica que está isenta de contaminação, quando existir tratamento adequado. Acaba o processo com a secagem da carga.

Diferença entre os dois métodos

Segundo Pinto (2005, p.15):

A autoclavagem, ou tratamento do resíduo da saúde por autoclave, consiste em introduzir os sacos (embalagens lacradas) de lixo num sistema fechado, onde sem contato manual as embalagens são desfeitas (rasgadas), o lixo é triturado e submetido a cerca de 120 a 150 graus centígrados e pressão por alguns minutos. $O$ equipamento se assemelha a um autoclave que desinfeta por pressão de vapor d'água quente e calor. Para o leigo, digamos, é como uma panela de pressão, pois na realidade "desinfeta" e esteriliza o produto lixo hospitalar por cozimento.

Existem algumas desvantagens, como por exemplo, o fato de que trabalha sob pressão, o que implica certo risco. Por esse motivo pode aumentar o volume dos resíduos pelo cozimento e hidratação e, se existir instrumento metálico no meio dos resíduos, poderá quebrar a máquina. A manutenção é cara e especializada, podendo causar danos ou prejuízos financeiros às empresas.

Quanto à incineração, se houver perfeita neutralização dos gases e vapores, segundo o mesmo autor, é o método mais perfeito e seguro, pois:

- as temperaturas permanecem entre $800^{\circ} \mathrm{C}$ e $1.200^{\circ} \mathrm{C}$;

- não há necessidade de abertura das embalagens, nem de trituração dos resíduos;

- o volume inicial é reduzido drasticamente, chegando a 3\% (três) por cento do volume inicial; e

- o sistema de tratamento térmico com lavagem alcalina dos gases e vapores dispensa manutenção.

Vale ressaltar que cada caso deve ser analisado separadamente, estudando-se os benefícios e desvantagens, verificando-se os tipos e quantidades de resíduos a serem tratados, para só então optar pelo método mais adequado. Tanto um quanto outro implicam alguns riscos.

\section{Estudo de caso}

A empresa estudada constitui-se em uma sociedade de economia mista e é constituída por quatro hospitais, todos vinculados ao Ministério da Saúde. Para a finalidade desta pesquisa foi analisada uma das unidades hospitalares pertencentes ao grupo.

Trata-se de uma unidade de trauma que atende às seguintes especialidas médicas e cirúrgicas: ortopedia, traumatologia, pediatria, anestesiologia, clínica médica, neurocirurgia, cirurgia do trauma, cirugia plástica, microcirurgia, cirurgia buco-maxilo-facial e cirurgia vascular.

A entidade citada tem 50 anos de fundação. Quanto à sua estrutura física, possui $18.835 \mathrm{~m}^{2}$ e 281 leitos. No que diz respeito aos recursos humanos, possui 1.120 funcionários. 
Após o conhecimento do ambiente onde se está atuando e a descoberta das situações in loco, através de entrevistas semi-estruturadas, fez-se a análise dos resultados, obedecendo às fases do método Gaia (Gerenciamento de Aspectos e Impactos Ambientais). Na primeira fase, sensibilização, aplicou-se a sustentabilidade do negócio, através da lista de verificação, conforme o quadro 9. 


\section{Quadro 9 - Lista de verificação da unidade hospitalar}

\section{CRITÉRIO 1 - FORNECEDORES}

1.0 processo hospitalar segue a legislação ambiental? SIM NÃO NA OBSERVAÇÕES

2.Os fornecedores são monopolistas no mercado?

A

3.Os fornecedores apresentam preocupação com o meio ambiente?

A

4. Para a extração/transporte/processamento/distribuição da matéria-prima é necessário grande consumo de energia?

D SÓ A INCOTERM

A

5. Os fornecedores apresentam alternativas para o tratamento de resíduos?

CRITÉRIO 2 -ECOEFICIÊNCIA DO PROCESSO HOSPITALAR

\section{A) INCINERAÇÃO DE RESÍDUOS}

6. A incineração é utilizada para o tratamento de todos os resíduos?

7. A incineração é utilizada para o tratamento de resíduos de alta periculosidade?

D

8. É verificado se existe a destruição completa e segura nesse processo?

9.Esse método é de alto custo?

NA

10. É necessária a utilização de equipamentos especiais?

NA

11. As escórias e cinzas, resultantes do processo, são dispostas em aterro

sanitário próprio?

NA

12. Os efluentes líquidos são encaminhados para estação de tratamento?

13. Os gases oriundos da queima são tratados e monitorados?

NA

14. O lixo hospitalar é acondicionado em sacos plásticos lançados manualmente em pequenos incineradores?

15. É realizada também a incineração a céu aberto?

$\mathrm{D}$

B) AUTOCLAVAGEM

16.A instituição também utiliza essa forma de tratamento?

A

REALIZADO PELA

ABORGAMA

17.O lixo é coletado em sacos plásticos, na cor branco leitosa, conforme especificação da norma ABNT, ou nos recipientes apropriados?

A

18.Os sacos de lixo são depositados em caixas metálicas sem tampa, sem que haja a necessidade de abri-los?

A

19.O vapor é injetado na câmara para permitir a esterilização propriamente dita?

$\mathrm{D}$

CAIXAS PLÁSTICAS

20.O lixo é triturado e encaminhado para um aterro sanitário para depositação final?

NA

NA

NA

21.O lixo triturado, ensacado ou em container é armazenado sobre base impermeabilizada com caimento para caixa de coleta, para recolher o chorume?

A BASE É DE MATERIAL

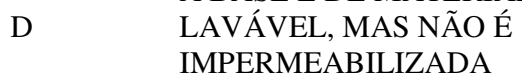

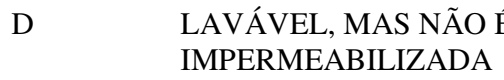

22..Os líquidos que resultarem da lavagem dos containers e do triturador são encaminhados para a mesma caixa de coleta?

\begin{tabular}{ll}
\hline 23. Os efluentes são tratados? & D
\end{tabular}

24. É realizada a secagem da carga, permitindo assim a retirada da mesma sem respingos?

NA REALIZADO NA

ABORGAMA

D

D

$\mathrm{D}$

CRITÉRIO 3 - TRATAMENTO COM PACIENTES

25.Existe estrutura física adequada para o tratamento de pacientes?

A

26. Os recursos humanosa disponíveis são suficientes para atendimento aos pacientes?

NA

\section{A}


27 Os pacientes tem conhecimento do que seja valorização ambiental?

$\mathrm{D}$

28.Existe acompanhamento psicológico dos pacientes com problemas mais graves?

$\begin{array}{ll}\text { 29.Existe separação por setor para os pacientes com doenças contagiososas? } & \text { D ESPECÍFICA PARA }\end{array}$

\section{CRITÉRIO 4 - INDICADORES GERENCIAIS}

30. A organização está submetida a uma intensa fiscalização por parte dos órgãos ambientais municipais, estaduais e federais?
A

ANVISA E FEPAM

31. A organização é ré em alguma ação judicial referente à poluição ambiental, a acidentes ambientais e/ou indenizações trabalhistas decorrentes?

A

\begin{tabular}{|c|c|c|}
\hline $\begin{array}{l}\text { 32. Já ocorreram reclamações sobre aspectos e impactos do processo hospitalar } \\
\text { por parte da comunidade vizinha? }\end{array}$ & $\mathrm{D}$ & $\begin{array}{l}\text { RECLAMAÇÃO SOBRE A } \\
\text { FULIGEM DA CALDEIRA }\end{array}$ \\
\hline 33. Ocorreram acidentes ou incidentes ambientais no passado? & A & \\
\hline 34. São realizados investimentos sistemáticos em proteção ambiental? & $\mathrm{D}$ & \\
\hline $\begin{array}{l}\text { 35.A eficiência de utilização de insumos e matérias-primas é relativamente } \\
\text { observada? }\end{array}$ & $\mathrm{D}$ & \\
\hline
\end{tabular}

36. A quantidade mensal de matérias-primas e energia utilizadas por processo hospitalar é crescente?

$\mathrm{D}$

\section{CRITÉRIO 5 - RECURSOS HUMANOS NA ORGANIZAÇÃO}

37. Os gestores estão cientes da poluição do ar pelos gases da combustão e por partículas não retidas nos filtros e precipitadores?
A

A

A

39. Os gestores acreditam que a carga orgânica pode estar isenta de contaminação?

40. A alta administração se mostra efetivamente comprometida com a gestão ambiental?

$\mathrm{D}$

41. O corpo gerencial se apresenta efetivamente comprometido com a gestão ambiental?

\begin{tabular}{ll}
\hline 42. A mão-de- obra empregada é altamente especializada? & D \\
\hline 43.Os colaboradores estão voltados a inovações tecnológicas? & D
\end{tabular}

44.A criatividade é um dos pontos fortes da organização e de seus colaboradores?

45.Existe uma política de valorização do capital intelectual?

Fonte:adaptado de Lerípio (2001, p.68)

D

$\mathrm{D}$

$\mathrm{D}$

$\mathrm{D}$

$\mathrm{D}$

Foram entrevistados os profissionais envolvidos na unidade hospitalar. O preenchimento da lista de verificação teve a colaboração de um gestor da área técnica e de outro da área administrativa. Passou-se ao estudo, determinando a condição de "A" para "adequado", "D" para "deficitário" e de "NA" para aquelas questões que não se adaptavam à empresa pesquisa. Em seguida, apurou-se a sustentabilidade de cada critério e subcritério, mostrando os trâmites da empresa, dentro de cada atividade, conforme mostra o quadro 10. 


\section{Quadro 10 - Sustentabilidade parcial por critério e subcritério da empresa pesquisada}

\begin{tabular}{lll}
\hline Critério & Subcritério & Sustentabilidade \\
\hline Fornecedores & $-\mathrm{x}-$ & $300 / 5=60 \%$ \\
\hline \multirow{2}{*}{ Ecoeficiência do processo hospitalar } & A) Incineração de resíduos & $100 / 3=33,33 \%$ \\
\cline { 2 - 3 } & B) Autoclavagem & $200 / 7=28,57 \%$ \\
\hline Tratamento com pacientes & $-\mathrm{x}-$ & $300 / 5=60 \%$ \\
\hline Indicadores gerenciais & $-\mathrm{x}-$ & $300 / 7=42,86 \%$ \\
\hline Recursos humanos na organização & $-\mathrm{x}-$ & $300 / 9=33,33 \%$ \\
\hline
\end{tabular}

Fonte: adaptado de Pfitscher (2004, p.83).

Obteve-se, assim, uma sustentabilidade global de 43,02\%; sustentabilidade parcial do critério um, $60 \%$; do critério dois, 30,95\%, sendo 33,33\% do primeiro subcritério - "incineração de resíduos" e do segundo, 28,57\%, relativo a "autoclavagem". Quanto ao terceiro critério, obteve-se $60 \%$; ao quarto, $42,86 \%$ e ao quinto, 33,33\%. A maior preocupação está no segundo critério, "ecoeficiência do processo hospitalar".

Segundo Lerípio (2001, p.68), o referencial para a classificação da sustentabilidade segue um resultado classificado em cores e adaptado por Pfitscher (2004, p.84) em letras, sendo acima de 91\% - "ótima-O", entre 71 e $90 \%$-"adequada-A", entre 51 e 70\% -"regular-R" e inferior a 50\% - "deficitária-D".

No caso específico da empresa pesquisada, a sustentabilidade global revela-se "deficitária", sendo o critério um - "regular", o critério dois - "deficitário", o critério três - "regular", o critério quatro - "deficitário" e o critério quinto, também, "deficitário".

Em continuidade, fez-se a correlação entre sustentabilidade e desempenho ambiental, desenvolvendo, assim, a segunda atividade, estratégia ambiental (segunda parte da fase de sensibilização). Obteve-se, numa visão macro, uma situação de nível de desempenho "deficitário", baseado no quadro 2, mostrando falta de esforço para controlar a poluição, podendo estar causando danos ao meio ambiente. Relaciona-se, nesse momento, o critério com maior necessidade de atendimento, que no caso em pauta é o critério "dois".

Assim, iniciaram-se novos trabalhos envolvendo, nesse momento. a terceira atividade, comprometimento e sensibilização das partes interessadas (terceira parte da fase sensibilização). Foram direcionados esforços para que a empresa estudada reestruture sua missão, visão e política.

Adiante, estuda-se a fase de conscientização, na qual, além do mapeamento de cadeia de produção e consumo, verifica-se o mapeamento do macrofluxo do processo e estudo das entradas e saídas dos processos e inventário de aspectos e impactos ambientais, conforme mostra o quadro 11.

Quadro 11- Planilha de identificação e priorização de aspectos e impactos ambientais

\begin{tabular}{|c|c|c|c|c|c|c|c|c|c|c|c|c|c|c|c|c|}
\hline \multirow[t]{2}{*}{ Atividade } & \multirow[t]{2}{*}{ Aspecto } & \multirow[t]{2}{*}{ Impacto } & \multicolumn{8}{|c|}{ Preocupações comerciais } & \multicolumn{4}{|c|}{$\begin{array}{c}\text { Preocupações } \\
\text { ambientais }\end{array}$} & \multirow[t]{2}{*}{$\mathbf{T}$} & \multirow[t]{2}{*}{$\mathbf{P}$} \\
\hline & & & EL & FC & CA & $\mathbf{E}$ & $\mathbf{P P}$ & EI & $\begin{array}{l}\text { Sub- } \\
\text { total } \\
\text { Média }\end{array}$ & $\mathbf{E}$ & $\mathbf{S}$ & PO & $\begin{array}{l}\text { D/ } \\
\mathbf{P}\end{array}$ & $\begin{array}{c}\text { Sub- } \\
\text { total } \\
\text { Média }\end{array}$ & & \\
\hline $\begin{array}{l}\text { 1. Recebimento do } \\
\text { lixo }\end{array}$ & $\begin{array}{c}\text { Material em } \\
\text { decomposição }\end{array}$ & $\begin{array}{c}\text { Poluição do ar } \\
\text { e dos } \\
\text { efluentes }\end{array}$ & 3 & 5 & 3 & 5 & 3 & 3 & 223,7 & 3 & 5 & 5 & 5 & $18 \quad 4.5$ & 9,2 & 1 \\
\hline
\end{tabular}

Fonte: adaptado de Pfitscher et al (2002, p.25). 
Num primeiro momento, estudou-se por amostragem, o critério dois, que está dividido em dois subcritérios: incineração e autoclavagem. $O$ primeiro mostrou um resultado melhor, tendo em vista a grande quantidade de "NA", por a empresa não adotar esse método, pois algumas instituições adotam a incineração e a autoclavagem e a empresa estudada.adota somente a autoclavagem, que passa a ser o foco deste estudo.

Para o preenchimento da planilha de identificação e priorização de aspectos e impactos ambientais, utilizam-se raciocínios ilustrativos, como por exemplo: o lixo, que é triturado e não encaminhado para um aterro sanitário para depositação final, apresenta uma situação extremamente crítica (5), crítica (4), moderada (3), desprezível (2) ou totalmente desprezível (1)? A planilha mostrou como prioridade o atendimento ao lixo hospitalar, que tem sido disposto de forma irregular. Outros aspectos que merecem atenção especial dizem respeito aos critérios "recursos humanos na organização" e "indicadores gerenciais".

Assim, dando sequência, passa-se para a terceira fase, capacitação ou qualificação, na qual são identificadas as oportunidades de melhoria, estudo de viabilidade técnica, econômica e ambiental e o planejamento, conforme mostra o quadro 12.

\section{Quadro 12 - Plano resumido de gestão ambiental}

\begin{tabular}{|c|c|c|c|c|c|c|}
\hline $\begin{array}{l}\text { What? O } \\
\text { que? }\end{array}$ & $\begin{array}{l}\text { Why? Por } \\
\text { quê? }\end{array}$ & $\begin{array}{l}\text { When? } \\
\text { Quando? }\end{array}$ & $\begin{array}{l}\text { Where? } \\
\text { Onde? }\end{array}$ & Who? Quem? & How? Como? & $\begin{array}{l}\text { How much? } \\
\text { Quanto } \\
\text { custa? }\end{array}$ \\
\hline $\begin{array}{l}\text { Tratamento e } \\
\text { reutilização de } \\
\text { resíduos } \\
\text { sólidos }\end{array}$ & $\begin{array}{l}\text { Evitar impacto } \\
\text { agravante }\end{array}$ & $\begin{array}{l}\text { Início no } \\
\text { primeiro } \\
\text { semestre de } \\
2006\end{array}$ & $\begin{array}{l}\text { Na empresa e } \\
\text { instituições } \\
\text { qualificadas }\end{array}$ & $\begin{array}{l}\text { Gestores da } \\
\text { empresa } \\
\text { pesquisada e } \\
\text { extensionistas }\end{array}$ & $\begin{array}{l}\text { Benchmarking } \\
\text { ambiental } \\
\text { sobre resíduos } \\
\text { hospitalares }\end{array}$ & $\begin{array}{l}\text { O orçamento } \\
\text { inicial está } \\
\text { em } \\
\mathrm{R} \$ 35.903,00\end{array}$ \\
\hline $\begin{array}{l}\text { Cursos de } \\
\text { qualificação }\end{array}$ & $\begin{array}{l}\text { Implantar um } \\
\text { novo método } \\
\text { de gestão }\end{array}$ & $\begin{array}{l}\text { Início no } \\
\text { primeiro } \\
\text { semestre de } \\
2006\end{array}$ & $\begin{array}{l}\text { Área de } \\
\text { recursos } \\
\text { humanos } \\
\text { técnico } \\
\text { administrativos } \\
\text { e gestores da } \\
\text { empresa }\end{array}$ & $\begin{array}{l}\text { Pesquisadores e } \\
\text { extensionistas }\end{array}$ & $\begin{array}{l}\text { Preparo de } \\
\text { palestras de } \\
\text { curta duração } \\
\text { e minicursos } \\
\text { sobre o novo } \\
\text { método }\end{array}$ & $\begin{array}{l}\text { O orçamento } \\
\text { inicial é de } \\
\mathrm{R} \$ 3.500,00 \text {, } \\
\text { correspondent } \\
\text { e a } 100 \text { horas }\end{array}$ \\
\hline
\end{tabular}

Fonte: Pfitscher (2004, p. 99).

Verifica-se, então, que o plano resumido de gestão ambiental contemplou as metas e objetivos mostrados como prioritários para a empresa. Também as justificativas para o estudo foram entendidas como necessárias, em um processo de melhoria contínua. A ferramenta $5 \mathrm{~W} 2 \mathrm{H}$ mostrou ser uma estratégia de fácil entendimento. Pôde-se comprovar que as unidades hospitalares necessitam do apoio das instituições de ensino, para darem seqüência às suas atividades, valorizando o meio ambiente e proprocionando melhor qualidade dos serviços aos seus clientes.

\section{Conclusões e sugestões}

A gestão ambiental mostra a necessidade da ação do homem não provocar impactos nocivos ao meio ambiente. Assim, diante de problemas ambientais existem dificuldades para os gestores obterem informações confiáveis e fidedignas para a tomada de decisão. Além disso, a falta de conhecimento e de capacitação de funcionários faz com que muitas empresas, especialmente as unidades hospitalares, acabem por agredir o meio ambiente e proporcionar qualidade de serviços inadequada, levando, inclusive, a outras doenças, até tóxicas e cancerígenas. 
Pôde-se constatar que o Gaia (Gerenciamento de Aspectos e Impactos Ambientais) pode auxiliar os gestores dos hospitais, tornando as suas estruturas organizacionais mais confortáveis, se houver o envolvimento da sociedade. No decorrer desta pesquisa, muitas empresas (fornecedores) se mostraram interessadas em auxiliar, pois existe aí uma reciprocidade que pode levar não só à sustentabilidade ambiental, mas também à econômica.

Verificou-se também que essa unidade hospitalar não está utilizando o método mais adequado quanto à "ecoeficiência do processo hospitalar" pois, segundo pesquisadores citados na pesquisa, a "incineração" seria mais adequada, pois financeiramente é menos onerosa, consome menos energia e reduz a quantidade de resíduos a serem colocados em aterros em até 97\%. Também constatou-se que esse método é ambientalmente vantajoso, pois a "autoclave" elimina a contaminação biológica do resíduo, mas mantém contaminantes químicos e físicos que são encaminhados ao aterro sanitário, contaminando a água e o ar.

Outro fator que mostrou relevância foi o descontentamente da área de recursos humanos, mostrando uma sustentabilidade de 33,33\%, considerada "deficitária". Nas entrevistas, pôde-se perceber sua insatisfação e ao mesmo tempo interesse em auxiliar, se tiverem valorização dentro da instituição. Assim, acredita-se que o trabalho tenha contribuido para a instituição pesquisada e para seus funcionários, como também pode servir como benchmarking ambiental e educacional para outras instituições desse mesmo ramo de atividade.

Sugere-se para trabalhos futuros, aprofundar estudos sobre serviços executados pelas clínicas hospitalares e os processos de controle de resíduos, necessários para novos estudos nos hospitais.

Outra sugestão seria aprofundar a metodologia Gaia, com envolvimento da área de contabilidade e controladoria ambiental, mostrando as vantagens financeiras que as instituições podem vir a obter, principalmente, pela divulgação de suas atividades na valorização do ser humano e do meio ambiente. 


\section{Referências}

BAUMER. Autoclave para tratamento de resíduos infecciosos. Disponivel em: <http://www.baumer.com.br/mwts/Portugues/Mwts_Tecnico.htm>. Acesso em: 20 fev. 2006.

BEUREN, I. M. 0 papel da controladoria no processo de gestão. In: CONTROLADORIA - agregando valor para a empresa. São Paulo: Bookmann Cia Editora, Divisão Artmed Editora S.A.2002.

ESSENCIS. Serviços: incineração. Disponivel em: <http://www.essencis.com.br/serv_inc.asp>. Acesso em: 20 fev. 2006.

INCINERAÇÃO do lixo dos serviços de saúde e hospitalar. Disponível em: <http://lixohospitalar.vilabol.uol.com.br/Incineracao_do_lixo.html>. Acesso em: 20 fev. 2006.

LERÍPIO, A. A. Gaia - um método de gerenciamento de aspectos e impactos ambientais. Tese (Doutorado em Engenharia de Produção) Universidade Federal de Santa Catarina, Florianópolis, 2001.

MECHLER, W.A. P. Eng., Greater Vancouver. Regional District, jun 1991.

MERRIAM, S. Qualitative research and case study applications in education. San Francisco, CA: Jossey-Bass, 1998.

PFITSCHER, E. D. Gestão e sustentabilidade através da contabilidade e controladoria ambiental: estudo de caso na cadeia produtiva de arroz ecológico. Tese (Doutorado em Engenharia de Produção) - Universidade Federal de Santa Catarina, Florianópolis, 2004.

et al. 0 sistema de gestão ambiental e o aproveitamento de resíduos: um estudo de caso do arroz ecológico à partir da aplicação do método Gaia. Trabalho de disciplina (Engenharia de Produção) - Universidade Federal de Santa Catarina, Florianópolis, 2002.

PINTO, A. G. G. Tratamento térmico dos resíduos orgânicos com lavagem alcalina dos gases e vapores. Ambiente Brasil, 22 dez. 2005. Disponivel em: <http://www.ambientebrasil.com.br/noticias/index.php3?action=lerEtid=22326>. Acesso em: 20 fev. 2006.

SBRT - Serviço Brasileiro de Respostas Técnicas. Como é o tratamento de lixo hospitalar, de que forma é realizado? Disponível em: $<$ http://sbrt.ibict.br/upload/sbrt2073.pdf>. Meio ambiente, reciclagem e tratamento de resíduos - Formulário de Resposta Técnica Padrão 1. São Paulo, 2006.

TACHIZAWA, T. Gestão ambiental e responsabilidade social corporativa: estratégias de negócios focadas na realidade brasileira. São Paulo: Atlas, 2004.

WASTE Information System, AO0, 1992. SBRT - Formulário de Resposta Técnica Padrão 4.

IBICT - Instituto Brsileiro de Informação em Ciência e Tecnologia http://www.sbrt.ibict.br 